\title{
论文
}

\section{史前农业传播: 从中国南方到中南半岛}

\author{
高玉 ${ }^{1}$, 董广辉 ${ }^{2,3}$, 杨晓燕 ${ }^{1,3^{*}}$, 陈发虎 ${ }^{1,2,3}$ \\ 1. 中国科学院青藏高原研究所中国科学院高寒生态重点实验室, 北京 100101; \\ 2. 兰州大学西部环境教育部重点实验室, 兰州大学资源环境学院, 兰州 730000; \\ 3. 中国科学院青藏高原地球科学卓越创新中心, 北京 100101 \\ * 通讯作者, E-mail: xyang@itpcas.ac.cn
}

收稿日期：2019-04-12; 收修改稿日期：2019-09-27; 接受日期：2019-11-18; 网络版发表日期：2020-02-24 国家自然科学基金项目(批准号: 41901108和41930323)、第二次青藏高原综合科学考察研究项目(编号: 2019QZKK0601)和中国科学院战略性 先导科技专项(A类)项目(编号: XDA2004010103)资助

摘要农业的发展与传播是人类历史上最重大的变革之一，史前农业向中南半岛的扩散关系到现今南亚语族的 形成，是农业传播领域的重要科学问题。以往大部分研究集中在稻作农业传入东南亚的时间和路线上，而粟作农 业没有得到应有的重视. 本文梳理了中国和中南半岛 128 个遗址出土的 312 个稻(Oryza sativa)、粟(Setaria italica) 和秘(Panicum miliaceum)遗存的直接测年数据, 发现中南半岛于公元前三千纪后期出现粟作农业, 至迟于公元前 二千纪后期出现稻作农业. 经分析, 我们认为中南半岛的早期农业可能有中国西南、两广地区和福建沿海三个来 源。史前农业在中国西南地区的传播路线与文献记载的“西南丝绸之路”非常接近，这表明在新石器晚期青藏高原 东缘就存在一条文化通道, 为后世西南丝绸之路的开通奠定了基础.

关键词中南半岛, 中国南方, 农作物传播, 史前时代, 西南丝绸之路

\section{1 引言}

跨大陆尺度的文化交流与碰撞是人类社会发展的 推动力之一(Sherratt, 2006), 所以史前文化的全球化一 直是备受学界和社会关注的科学问题. 近年的研究表 明，史前欧亚大陆上可能并存着几条不同的东西方向 的文化通道，由此带来了物种、技术和观念上的流动 与传播, 对欧亚大陆新石器晚期-青铜时代(4500 $3000 \mathrm{a}$ BP) 的整体发展起到了至关重要的作用(Jones 等, 2011; 张弛, 2017; 陈发虎等, 2017). 实际上, 史前 时期欧亚大陆东部南北方向的文化交流同样活跃．考 古发现表明，旧石器时代南中国与中南半岛的文化面
貌就存在诸多相似之处，早中期同属于粗大的砾石石 器工业, 晚期开始出现小型的石片工业 (王幼平, 1997); 新石器时代源于中国南方的绳纹陶器在东亚、 东南亚和南亚分布广泛, 显示出跨区域尺度的文化互 动(Kharakwal等, 2004); 新石器晚期到青铜时代来自 北方的移民给中南半岛输入了人口和新的生计方式 (Diamond和Bellwood, 2003; Lipson等, 2018; McColl等, 2018; Matsumura等, 2019). 这些研究初步勾勒出中国 南方与中南半岛史前文化交流的轮廓.

然而目前对早期农业向东南亚传播过程的认识尚 有不足(本文所说的农业指稻、粟谷物农业). 现在学界 普遍认同野生稻最初在长江中、下游被驯化为粳稻 
(Oryza sativa subsp. japonica)(周拾禄，1948; Second, 1985; 严文明，1990; 孙传清等，1997; Fuller，2011; Larson等, 2014), 粟(Setaria italica)和㯟(Panicum miliaceum)的驯化中心在中国北方( $\mathrm{Lu}$ 等, 2009; Yang等, 2012), 中南半岛史前遗址出土的稻米/稻壳的古DNA 检测结果都是粳稻(Bellwood等, 2011; Castillo等, 2016). 所以, 中南半岛稻作和粟作农业的源头无疑在 中国. 关于史前农业向中南半岛传播的路线和时间 (Higham，1996; Zhang和Hung，2010； Fuller等，2010; Silva等, 2015)还有进一步讨论的余地. 近年来随着中 国南方和中南半岛植物考古和 ${ }^{14} \mathrm{C}$ 年代数据的积累, 为 复原史前农业向中南半岛的传播历史提供了重要材料.

\section{2 材料与方法}

本文拟通过梳理中南半岛与毗邻的中国西南(包 括四川、云南、贵州)与华南地区(包括广东、广西、 福建和台湾)出土的谷物遗存材料(见图1和表1), 复原 稻作和粟作向南传播的时空过程, 以深化对史前时期 两地文化交流的认识.

由于遗址保存环境和考古工作的差异，导致现有 的植物考古材料地区分布非常不平衡，如四川地区已 有大量系统浮选结果发表, 而桂东粤西一带仅有零星 的植硅体和采集的陶片夹杂稻壳的记录. 本文主要研 究对象为稻、粟类大植物遗存, 将优先选择有直接测 年的材料, 这是讨论早期农业向中南半岛传播最直接 有力的证据; 其次是未经直接测年, 但是有大量地层 关系和其他测年数据佐证的. 如果某地植硅体或淀粉 粒等微体植物遗存材料早于当地植物大遗存的年代框 架, 再采纳微体遗存的材料进行分析. 具体方法是分别 梳理出各地区的早期作物遗存, 先依据植物遗存建立 逻辑上的传播过程, 再结合当地的考古学文化背景, 勾勒早期农业从中国南方向中南半岛的传播过程.

\section{1 中南半岛}

位于泰国南部的Khok Phanom Di遗址不仅发现了 稻属植硅体, 还在陶器掺合料中发现了稻壳, 对两个陶 片中夹杂的稻壳直接测年，结果分别为5039 4646和 4826 4438cal a BP(校正年代，以下同)(Thompson, 1996; Ramsey等, 2002). 相距不远的Nong Nor遗址是 一处青铜时代墓地, 研究者对五座墓葬出土陶器夹杂
的稻壳进行测年, 最早数据出自墓 105 , 为 3442 3000cal a BP(Hedges等，1993). 泰国东北部地区Non Nok Tha遗址墓 3 出土炭化稻的测年结果为 3445 3071 cal a BP(Hedges等, 1991). 其他有水稻直接年代 的, 如Ban Non Wat等遗址, 测年结果都落在公元前一 千纪或更晚(Higham和Higham, 2009).

早期的粟、乘遗存集中发现在泰国的Khao Wong Prachan(KWP)流域, 该地区Non Pa Wai、Nil Kham Haeng和Non Mak La三个遗址早期阶段皆以粟作为主, 晚期才开始出现稻和粟的组合. 最早的粟来自Non Pa Wai遗址, 直接测年结果为4417 4158cal a BP(Weber等, 2010). 除此之外, 越南南部的Rach Nui(3555 3265a BP) 和马来半岛的Khao Sam Kaeo(2400 2100a BP)遗址都 出土了炭化粟(Oxenham等, 2015; Castillo, 2017; Castillo 等, 2018), 但未经直接测年. 另外, 植物微体分析显示在 公元前二千纪的很多遗址都发现了乘亚科植硅体 (Kealhofer和Piperno, 1994; Kealhofer和Grave, 2008).

\section{2 中国西南}

中国西南地区最早的水稻遗存来自成都平原, 新 津宝墩遗址出土水稻直接测年结果为4790 4432 cal a BP(d'Alpoim Guedes等, 2013), 桂圆桥遗址出土稻壳的 直接年代是4530 4250cal a BP(玳玉和万娇, 2015). 大 渡河中游的汉源龙王庙遗址经浮选发现了炭化稻、粟 和㯟, 年代约为4700 4500a BP(四川省文物考古研究 院等, 2011). 安宁河流域大兴横栏山遗址的新石器堆 积中出土有炭化稻、粟和㯟; 该遗址种子测年结果为 4470 4120 cal a BP, 但未言明测年材料是什么种子(成 都文物考古研究所等, 2016b). 金沙江中游的会理莲塘 遗址也有炭化稻出土, 直接年代为4160 3960 cal a BP (成都文物考古研究所等, 2016b). 云贵高原上最早的 水稻出自宾川白羊村遗址, 直接测年结果为4574 4424cal a BP(Martelloa等, 2018). 其他有直接测年的 水稻遗存, 鸡公山、吴家大坪、石岭岗、石佛洞等遗 址年代基本都在公元前两千纪以内 (贵州省文物考古 研究所等, 2006a, 2006b; 云南省文物考古研究所等, 2010; 黎海明等, 2016).

距今5000年前后的川西地区在金川刘家寨、马尔 康哈休和茂县营盘山遗址都发现了丰富的粟乘类遗存 (阿坝藏族芫族自治州文物管理所等, 2010; 赵志军和 陈剑, 2011; 李映福, 2014). 成都平原桂圆桥一期的植 


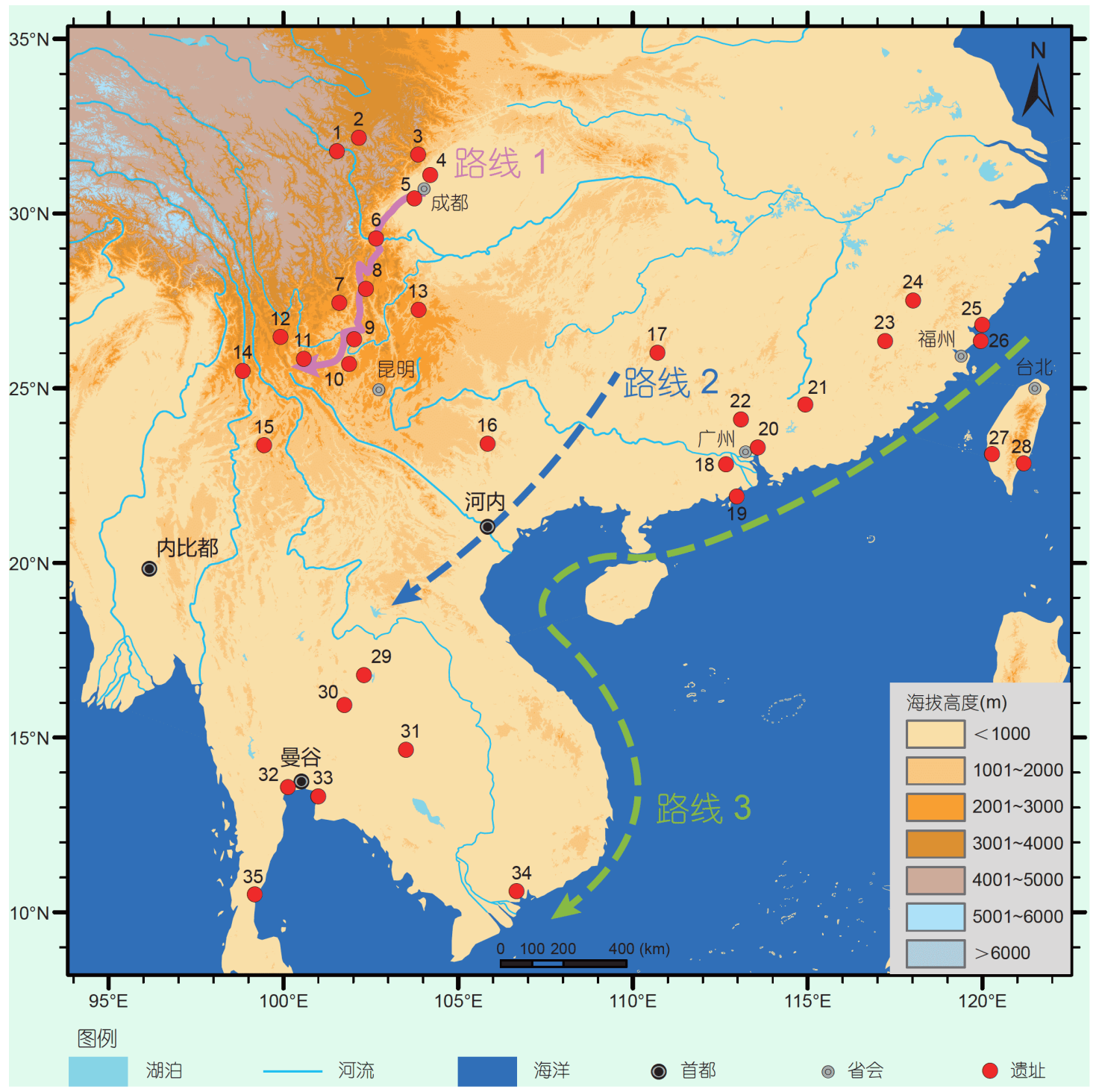

图 1 文中主要遗址及早期农业传播路线示意图

1, 刘家寨; 2 , 哈休; 3 , 营盘山; 4, 桂圆桥; 5 , 宝墩; 6 , 龙王庙; 7, 皈家堡; 8 , 横栏山; 9 , 莲塘; 10 , 大墩子; 11, 白羊村; 12, 海门口; 13, 鸡公山/吴家大 坪; 14, 石岭岗; 15, 石佛洞; 16, 感驮岩; 17, 晓锦; 18, 古梆; 19, 新村; 20, 茶岭; 21, 老院; 22, 石峡; 23, 南山; 24, 葫芦山; 25, 黄瓜山/屏风山; 26, 大 坪顶; 27, 南关里东; 28, 潮来桥; 29, Non Nok Tha; 30, Ban Non Wat; 31, Non Pa Wai/Nil Kham Haeng/Non Mak La; 32, Khok Phanom Di; 33, Nong Nor; 34, Loc Giang/An Son/ Rach Nui; 35, Khao Sam Kaeo

物遗存以粟和乘为主，其中㯟直接年代为 $4850 \sim 4550$ cal a BP(玳玉和万娇，2015). 以新津宝墩为代表的宝 墩文化遗址中都发现了粟秘类遗存, 通常与水稻同出, 年代应相当(石涛, 2012; d'Alpoim Guedes等, 2013). 龙 王庙遗址也出土了炭化的粟和㯟(四川省文物考古研 究院等, 2011). 盐源的家堡遗址植物遗存以粟㯟为主, 对乘直接测年的最早结果为4842 4644cal a BP(成都 文物考古研究所等, 2016a). 云贵高原上最早的粟出自
白羊村遗址一期, 直接年代为4818 4523cal a BP(Martelloa等, 2018). 大墩子、海门口等遗址出土的粟㯟遗 存基本在距今 4000 年以内(闵锐，2013; 金和天等, 2014). 需要说明的是云贵高原东南部那坡感驮岩遗址 二期(3800 2800a BP)出土的粟被鉴定为鸭掌粟(广西 壮族自治区文物工作队和那坡县博物馆，2003)，即非 洲起源的龙爪稷(Eleusine coracana). 耿马石佛洞遗址 (3400 3100a BP)在早年也有发现龙爪稷的报道(墽勇, 
表 1 中国南方和中南半岛的主要稻粟遗存及其年代 ${ }^{a)}$

\begin{tabular}{|c|c|c|c|c|}
\hline 区域 & 遗址 & 稻遗存年代(cal a BP) & 粟遗存年代(cal a BP) & 文献 \\
\hline \multirow{10}{*}{ 中南半岛 } & Nong Nor & 陶片中稻壳3442 3000* & N/A & Hedges等, 1993 \\
\hline & Non Pa Wai & 公元前一千纪 & $4417 \sim 4158^{*}$ & \multirow{3}{*}{ Weber等, 2010} \\
\hline & Non Mak La & 公元前一千纪 & 公元前两千纪 & \\
\hline & Nil Kham Haeng & $2756 \sim 2492^{*}$ & 公元前两千纪 & \\
\hline & Ban Non Wat & $2746 \sim 2459^{*}$ & N/A & Higham和Higham, 2009 \\
\hline & Non Nok Tha & $3445 \sim 3071^{*}$ & N/A & Hedges等, 1991 \\
\hline & Loc Giang & 陶片中穗轴4000 3300 & N/A & Barron等, 2017 \\
\hline & An Son & 陶片中穗轴4250 3150 & N/A & Bellwood等, 2011; Barron等, 2017 \\
\hline & Rach Nui & \multicolumn{2}{|c|}{$3555 \sim 3265+$} & Castillo等, 2018 \\
\hline & Khao Sam Kaeo & \multicolumn{2}{|c|}{$2400 \sim 2000+$} & Castillo等, 2016 \\
\hline \multirow{9}{*}{ 四川盆地 } & 刘家寨 & $\mathrm{N} / \mathrm{A}$ & $5500 \sim 4700$ & $\begin{array}{c}\text { 李映福, 2014; 四川省文物考古研究院等, } \\
2012\end{array}$ \\
\hline & 哈休 & N/A & $5500 \sim 4700$ & 阿坝藏族差族自治州文物管理所等, 2010 \\
\hline & 营盘山 & N/A & $5300 \sim 4600$ & 赵志军和陈剑, 2011 \\
\hline & 桂圆桥 & $4530 \sim 4250^{*}$ & $4850 \sim 4550^{*}$ & 玳玉和万娇, 2015 \\
\hline & 宝墩 & $4790 \sim 4432^{*}$ & 共存 & d'Alpoim Guedes等, 2013 \\
\hline & 龙王庙 & \multicolumn{2}{|c|}{$4800 \sim 4500+$} & $\begin{array}{c}\text { 间雪等, 2013; 四川省文物考古研究院等, } \\
2011\end{array}$ \\
\hline & 横栏山 & \multicolumn{2}{|c|}{$4470 \sim 4120+$} & 成都立物老士研空所筀 20161 \\
\hline & 莲塘 & $4160 \sim 3960^{*}$ & $4100 \sim 3970^{*}$ & 成都又物夸口研九胞寺, 20160 \\
\hline & 昄家堡 & N/A & $4842 \sim 4644^{*}$ & 成都文物考古研究院等, 2016a \\
\hline \multirow{8}{*}{ 云贵高原 } & 白羊村 & $4574 \sim 4424^{*}$ & $4818 \sim 4523^{*}$ & Martelloa等, 2018 \\
\hline & 大墩子 & $4139 \sim 3928^{*}$ & $4144 \sim 3880^{*}$ & 金和天等, 2014 \\
\hline & 海门口 & $3692 \sim 3571^{*}$ & $3966 \sim 3706^{*}$ & 闵锐, 2013 \\
\hline & 鸡公山 & $3444 \sim 3219^{*}$ & N/A & 贵州省文物考古研究所等, 2006a \\
\hline & 吴家大坪 & $3471 \sim 3166^{*}$ & N/A & 贵州省文物考古研究所等, 2006b \\
\hline & 石佛洞 & $3358 \sim 3066^{*}$ & 共存 & 云南省文物考古研究所等, 2010 \\
\hline & 石岭岗 & $2724 \sim 2384^{*}$ & 共存 & Zhang等, 2017 \\
\hline & 感驮岩 & $3859 \sim 3596^{*}$ & 共存 & $\begin{array}{c}\text { 广西壮族自治区文物工作队和那坡县 } \\
\text { 博物馆, } 2003\end{array}$ \\
\hline \multirow{4}{*}{ 两广 } & 晓锦 & 4500 & N/A & $\begin{array}{l}\text { 广西壮族自治区文物工作队和资源县 } \\
\text { 文物管理所, 2004; 张弛和洪晓纯, } 2009\end{array}$ \\
\hline & 茶岭 & $4526 \sim 4418^{*}$ & $\mathrm{~N} / \mathrm{A}$ & 夏秀敏等, 2019 \\
\hline & 老院 & $4690 \sim 4246^{*}$ & N/A & Yang等, 2018 \\
\hline & 石峡 & $4348 \sim 4091^{*}$ & $\mathrm{~N} / \mathrm{A}$ & Yang等, 2016 \\
\hline \multirow{6}{*}{ 闽台 } & 南山 & $4974 \sim 4846^{*}$ & 共存 & Yang等, 2018 \\
\hline & 葫芦山 & $3842 \sim 3649^{*}$ & 共存 & Ge等, 2019 \\
\hline & 黄瓜山 & $3980 \sim 3846^{*}$ & 共存 & \multirow{2}{*}{ Deng等, 2018a } \\
\hline & 屏风山 & $3826 \sim 3632^{*}$ & 共存 & \\
\hline & 南关里东 & $5000 \sim 4300$ & $5000 \sim 4300$ & Tsang等, 2017 \\
\hline & 潮来桥 & 植硅体4200 4000 & N/A & Deng等, $2018 b$ \\
\hline
\end{tabular}

a) ${ }^{*}$, 该年代为稻、粟遗存直接测年数据; $\mathrm{N} / \mathrm{A}$, 该遗址未发现此类作物遗存; 共存, 该遗址粟类作物与稻有共存关系, 年代应当同时; + , 粟 作和稻作的年代是一致的 
1983)，不过相关的照片资料不甚清晰无法进一步分 辨，且后续正式发掘中也不见龙爪稷(云南省文物考古 研究所等, 2010), 不能排除是早年鉴定的失误. 所以本 文暂且把这两例作为粟处理.

\section{3 中国华南}

两广内陆地区目前仅有资源晓锦遗址二期出土了 大量炭化稻, 但是该遗址部分测年数据与地层相矛盾, 推测年代在距今 4500 年以后(广西壮族自治区文物工 作队和资源县文物管理所，2004; 张弛和洪晓纯, 2009). 此外还有零星的水稻植硅体和采集的夹杂有稻 米、稻壳的陶片和红烧土证据, 年代存在争议, 大多也 晚于晓锦遗址(广东省文物考古所和封开县博物馆, 1998; 赵志军等, 2005; 向安强和姚锦鸿, 2006; 张文绪 等, 2008; 张弛和洪晓纯, 2009).

广东东部的台山新村遗址(5300 4420a BP)发现 了少量稻属植硅体，是采集的野生稻(Yang等，2013). 距今 5000 年前的高明古楖遗址有炭化稻出土, 然而出 自新石器地层的 3 粒水稻的测年结果落入了明清时代 (崔勇, 2007; Yang等, 2016). 广东地区确切的早期水稻 出自和平老院遗址(直接测年4690 4246cal a BP)(Yang 等，2018)和曲江石峡遗址(直接测年4290 4095cal a BP)(Yang等，2016). 珠三角地区的稻作年代稍晚，黄 埔茶岭遗址水稻的直接测年数据为 4526 4418cal a BP (夏秀敏等, 2019).

两广地区迄今尚未发现史前时期的粟㯟遗存.

福建闽侯大坪顶遗址墓 2 填土出土了 10 粒炭化稻, 直接测年数据为7571 7442cal a BP(吴卫, 2018). 明溪 南山遗址 4 号洞 19 23层发现了数以万计的植物种子 和果实, 并以水稻、粟、乘为主(中国社会科学院考古 研究所东南工作队等, 2018). 对22层出土水稻的直接 测年结果为4974 4846cal a BP(Yang等, 2018). 霞浦黄 瓜山和屏风山遗址(4200 4000a BP)出土了稻和粟类 的大植物遗存和植硅体遗存(Deng等, 2018a). 武夷山 葫芦山遗址浮选发现了水稻和粟，水稻的直接测年结 果为3842 3649cal a BP(Ge等, 2019). 台湾台南南关里 东遗址(5000 4300a BP)也发现了大量谷物遗存, 有水 稻、粟和㯟，但尚无谷物直接测年数据发表(Tsang等, 2017). 台东潮来桥遗址(4200 4000a BP)发现了驯化 形态的水稻扇形植硅体(Deng等, 2018b).

福建沿海地区出土的粟㯟遗存尚无直接测年数据,
但是明确的地层关系表明，南山、屏风山、黄瓜山、 南关里东、葫芦山等遗址的粟㯟与水稻遗存年代相当.

\section{3 结果}

中国和中南半岛已经发表的 ${ }^{14} \mathrm{C}$ 直接测年数据有 312 个, 包括 147 个水稻(图2)、165个粟和㯟(图3)的测 年结果.

将这些测年数据与出土地点结合起来，可以更直 观地反映谷物农业的传播过程. 由图2可知，自从水稻 被人类利用以来直到距今 5000 年前都局限在 $30^{\circ} \mathrm{N}$ 以 北, 即长江流域和中国北方地区. 在距今 4900 年大幅向 南扩展到 $26^{\circ} \mathrm{N}$ 左右, 结合经度分布, 可知向南扩展的 水稻有两支，一支到达福建沿海地区，一支到达云贵 高原. 约 1500 年后，水稻在距今 3400 年南进到 $13^{\circ} \mathrm{N}$ 即 中南半岛. 由图 3 可知, 粟㯟在距今 4800 年前都局限在 $35^{\circ} \mathrm{N}$ 以北，并在距今 4800 年大幅南进到 $27^{\circ} \mathrm{N}$, 即川西 山地; 很快推进到 $26^{\circ} \mathrm{N}$ 附近的云贵高原. 福建沿海的 粟作农业由于缺乏直接年代数据而没有体现在图3中, 但这是不可被忽视的一支. 粟作农业在距今 4400 年到 达 $15^{\circ} \mathrm{N}$ 一线, 即中南半岛.

简而言之, 稻粟农业向中国南方地区的传播路线都 可以分为东、西两路, 这两路都有可能是中南半岛农业 的来源. 需要说明的是, 大坪顶遗址出土水稻的年代在 距今 7500 年前后，研究者将其鉴定为人工栽培的粳稻 (吴卫，2018). 但仅通过稻米遗存的形态还难以对其驯 化/野生属性进行准确的判断，且该年代不符合当地生 业经济发展的整体框架, 故本文未采纳这一测年数据.

再看稻作、粟作农业到达中南半岛的时间. Non $\mathrm{Pa}$ Wai遗址的炭化粟测年结果与出土层位相吻合, 可 以确认粟作农业在距今 4400 年前开始出现在泰国东北 部. 位于越南南部的Rach Nui遗址和马来半岛的Khao Sam Kaeo遗址都有粟类遗存出土，表明粟作农业在东 南亚史前社会的生计中占有一定地位. 目前中南半岛 最早的、确丵的稻作证据是来自公元前两千纪晚期的 Non Nok Tha遗址. 虽然Khok Phanom Di遗址出土陶片 中夹杂稻壳直接测年结果是5039 4646 cal a BP, 但该 年代早于遗址体现的文化面貌且与出土地层相矛盾 (Ramsey等, 2002); Nong Nor遗址的测年结果有着同样 的问题(Hedges等, 1993), 故本文未予以采纳. Non Nok Tha遗址稻作出现年代比传统的认识要晚了很多. 传统 


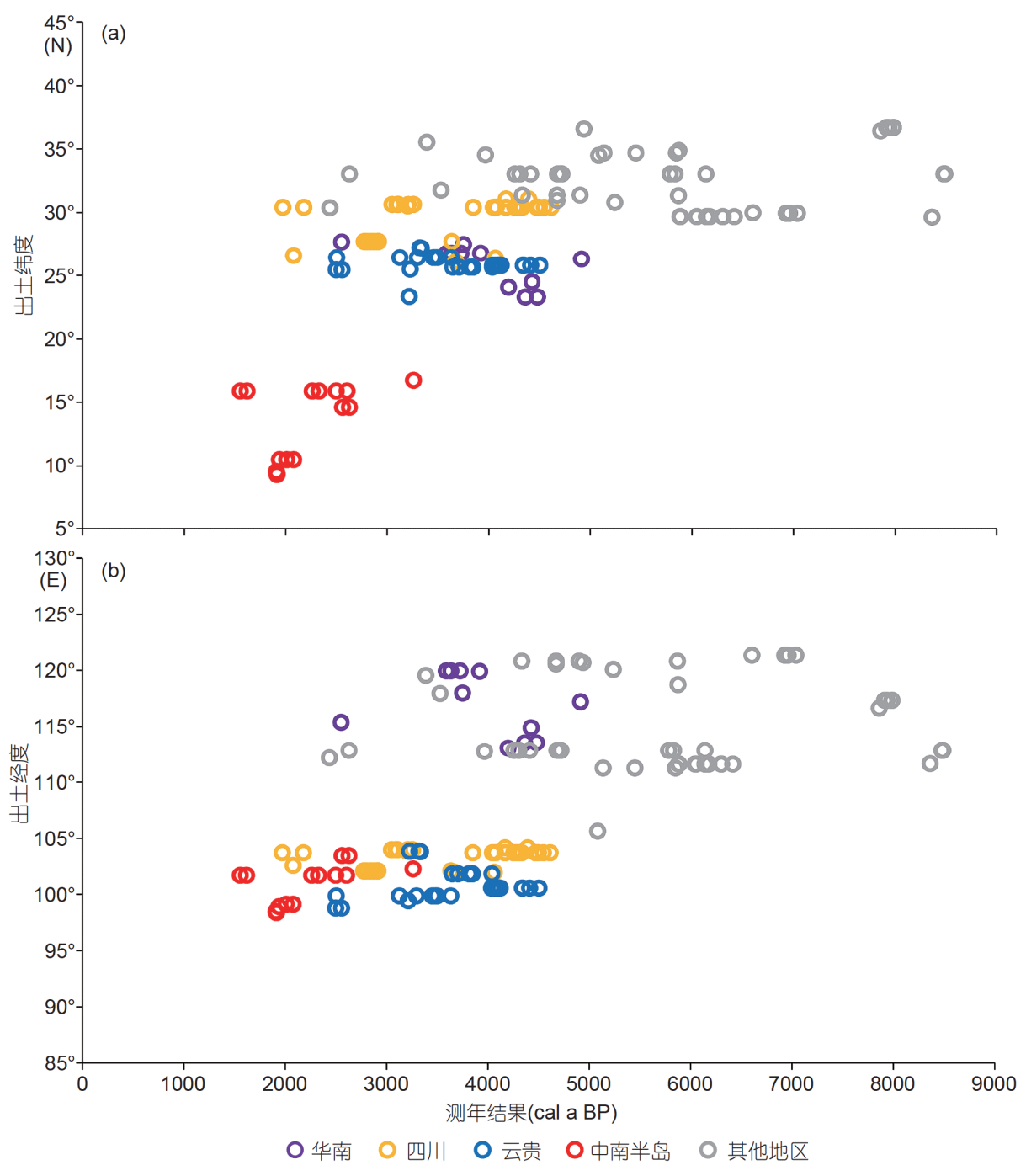

图 2 水稻遗存直接测年结果的纬度(a)和经度(b)分布

上认为中南半岛稻作农业出现在 4500 4000年前 (Higham, 2003), 但目前缺乏直接的实物证据. 故本文 暂且采用稻、粟最早的直接测年数据( $3400 \mathrm{cal}$ a BP和 4400cal a BP)作为中南半岛稻作和粟作农业开始出现 的时间. 这样的话, 稻作农业要晚于粟作而出现. 造成 这种现象的原因也许是更早的稻作遗存尚未被发现， 有赖于将来更多工作的开展.

\section{4 讨论}

\section{1 中南半岛早期农业的来源}

想要追溯中南半岛早期农业的来源, 需要在毗邻
的中国南方的、早于这个时间点的考古遗址中去寻 找. 而中国华南和西南地区都有早期稻作和粟作农业 的证据. 想要确定中南半岛史前农业的来源，还需结 合当地的考古学背景进行分析.

\subsection{1 华南地区}

在新石器晚期农业文化进入华南地区之前，广西 及毗邻的广东西部为原生的渔猎采集区，广东沿海在 长江中游等地的影响下形成了一种混生型的渔猎采集 文化; 福建沿海与粤东的情况类似, 当地最早的新石器 文化与长江中下游的早期文化有着密切联系. 不同的 文化渊源构成了后来稻作农业到达华南地区时的文化 


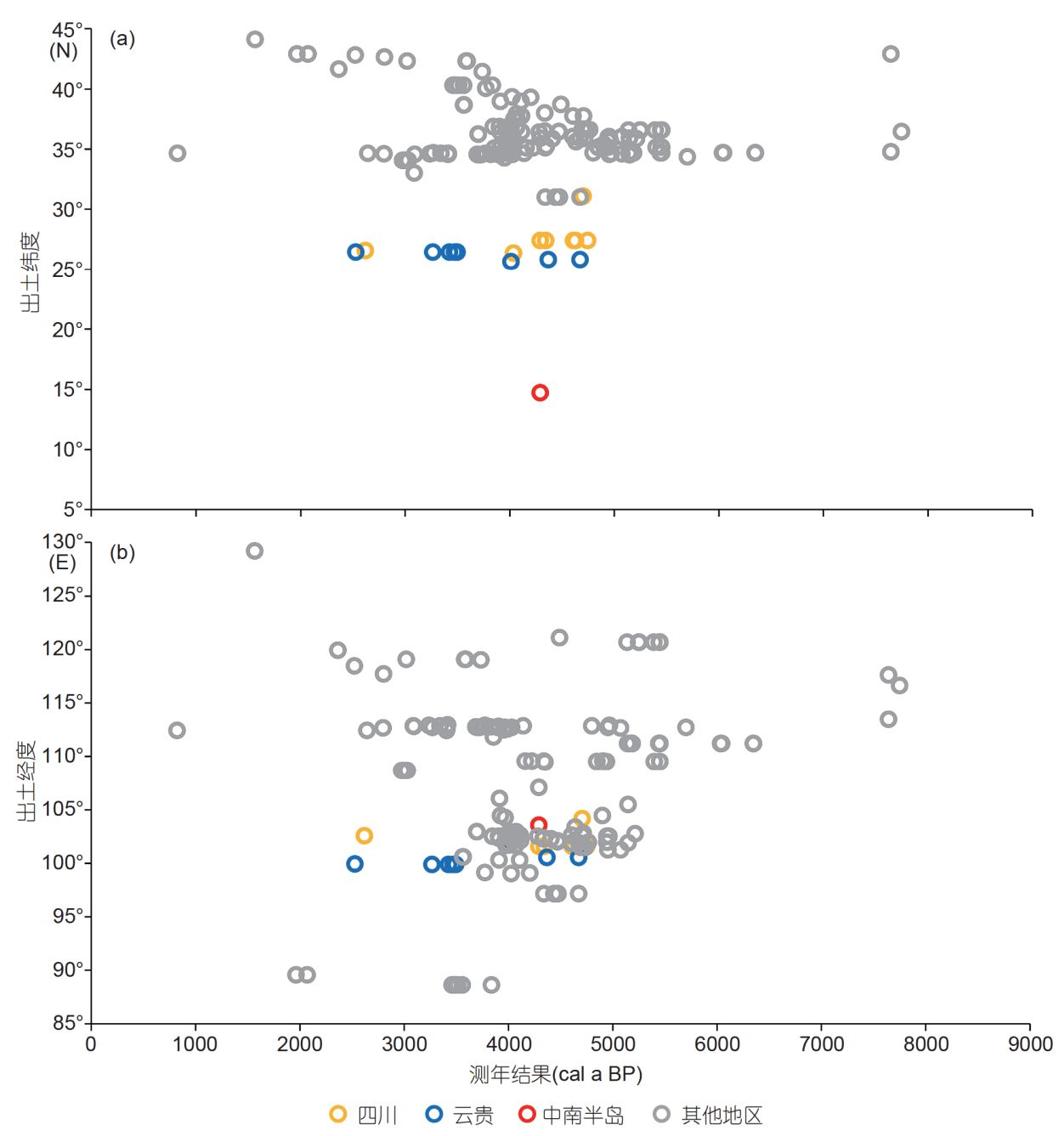

图 3 粟秘遗存直接测年结果的经度(a)和纬度(b)分布

基底(Zhang和Hung, 2012): 广东-福建沿海长期受有着 深厚的农耕文化底蕴的长江中下游的影响，一旦当地 有生计模式转变的需求/条件, 谷物农业可以沿着已有 的文化通道到达华南沿海地区; 广西-粤西长期处于独 立发展的状态, 文化面貌和人群相对单纯. 所以稻作农 业先行到达东部地区，这也与现有的植物考古证据相 吻合(Yang等, 2018; 夏秀敏等, 2019).

不过这仅解决了华南地区稻作农业之“源”，至于 “流”的问题, 需要考虑各地理单元与东南亚地区的关 系. 广西毗邻越南北部内陆, 属于同一地理单元. 在新 石器中期，广西、越南北部等地的渔猎采集文化属同 一文化系统. 福建沿海则与台湾岛和东南亚岛屿的文 化面貌更为接近，与中南半岛沿海地区也有相似之处.
这样看来中南半岛与两广的文化面貌更为接近. 然而 两广地区迄今仅有水稻遗存而无粟作遗存发现. 据此 仅能推出中南半岛的稻作农业有来自两广内陆的可能 性. 广东-福建沿海与中南半岛沿海文化的相似性, 加 之史前人类卓越的航行能力(Clarkson等, 2017), 暗示 从福建沿海地区到中南半岛南部之间或许存在一条海 上通道(Bellwood, 2011)(见图1). 考虑到中南半岛最先 出现的是粟作农业, 而广东东部史前阶段是单一的稻 作农业、福建沿海有稻粟兼作农业，这条海上通道的 源头很可能在福建沿海地区, 而后沿着大陆沿岸南下 到达中南半岛南部地区. 越南南部Loc Giang、An Son、Rach Nui等遗址确实发现了早于距今 3000 年前 的水稻遗存, 遗憾的是, 现在海岸地区还缺乏早于Non 
Pa Wai遗址的粟作农业证据.

\subsection{2 西南地区}

中国西南的新石器化开始于公元前四千纪中期, 深受“边地半月形文化传播带”上甘青地区的影响— 在川西大渡河上游和怅江上游地区的早期遗址都可以 看到马家窑文化的强烈作用(江章华, 2004). 在公元前 三千纪之初，来自西北的人群经由川西山地进入成都 平原，在距今 5000 年前形成了成都平原最早的新石器 文化一一桂圆桥一期遗存. 在桂圆桥一期末开始受到 来自东部长江中游和峡江地区文化的影响，逐步发展 出宝墩文化(4600 4000a BP)(万娇和雷雨, 2013; 何锟 宇, 2016). 云贵高原尚无完善的考古学文化谱系, 仅依 据地理位置和文化面貌被划分为不同的文化类型(王 大道, 1994; 李昆声, 1998), 年代较早的有洱海地区的 白羊村类型和滇池地区的石寨山类型，推测上限为距 今 5000 年; 其他类型的年代均不早于距今 4000 年 (肖明 华，2001). 成都平原和云贵高原之间山地的考古工作 有限，但在麦坪、横栏山、皈家堡等遗址的早期陶器 都与滇西的白羊村等遗址有着强烈的共性(万娇, 2013; 成都文物考古研究院等, 2016a), 表明新石器晚 期在青藏高原东南缘存在一定规模的文化交流.

成都平原的早期农业完全打上了文化的烙印。公 元前四千纪沿着半月形文化传播带南下的马家窑人把 粟作农业带到了川西地区，距今5000年前的茂县营盘 山、哈休、刘家寨等遗址都是单一的粟作农业(阿坝 藏族芫族自治州文物管理所等, 2010; 赵志军和陈剑, 2011; 李映福，2014)。这波人群很快进入到成都平原. 桂圆桥一期虽然有水稻遗存，但数量很少且仅有的一 个水稻直接测年结果落在了桂圆桥二期的年代范围 内，所以当时应该是单一粟作或以粟作为主的农业模 式. 这是建立在桂圆桥一期 4 个浮选样品的基础上, 还 有待更多材料的检验. 桂圆桥二期开始, 接受了来自长 江中游的稻作农业(孙华, 2009; 万娇和雷雨, 2013), 成 都平原自此呈现稻粟兼作的农业模式. 成都平原以南 的龙王庙、横栏山、莲塘等遗址在麦作传入以前都是 这种作物结构(四川省文物考古研究院等，2011; 成都 文物考古研究所等, 2016b), 应是成都平原农业向南传 播的结果.

云贵高原目前最早的系统的植物考古资料来自白 羊村类型的白羊村遗址(4600 4000a BP), 从早到晚的
植物组合都是稻、粟和㯟, 研究者认为它们很可能是 以作物组合的形式在公元前三千纪中期到达滇西北的 (Martelloa等, 2018). 其他开展过系统工作的遗址, 在麦 类作物传入以前, 都是稻粟组合的作物结构, 或许可以 作为推测云贵高原早期农业结构的参考. 总而言之, 中 国西南地区在距今 4500 年前就存在着成都平原-川西 山地-云贵高原这条文化与农业的传播通道，中国西南 很有可能是中南半岛稻作和粟作农业的源头.

\section{2 农业从中国西南向中南半岛的传播路线}

文献记载的“笔牛道”(又名“灵关道”，见图1路线 1), 与西南地区农业传播的通道非常接近. 施牛道是西 南丝绸之路中的一条通道, 大致路线为: 成都-邛崃-名 山-雅安-䓠经-汉源-甘洛-越西-喜德-冕宁-西昌-德昌米易-会理-攀枝花-云南永仁-大姚-大理(屈小玲, 2011). 成都平原和汉源地区都有早于 $4500 \mathrm{a} \mathrm{BP}$ 的稻粟兼作农 业; 西昌和会理地区虽然没有这么早的谷物遗存, 但是 在稍晚阶段(4400 4000a BP)的横栏山和莲塘遗址都 是稻粟组合的农业结构; 永仁附近的金沙江河谷, 新 发掘的丙弄丙洪等遗址与麦坪、白羊村等遗址文化面 貌近似，推测年代较为接近，上限应该在5000 4500a $\mathrm{BP}$ (私人交流). 这些零星的遗址点串联起来的路线表 明早在公元前三千纪晚期西南丝绸之路的前身即已开 通. 至于稻粟兼作农业从滇西北向中南半岛的传播路 线，由于处于中间地带的云贵高原南部和中南半岛北 部缺乏可以串联起两地的考古学或植物考古证据, 所 以现在还难以推论.

\section{3 早期农业向中南半岛传播的方式}

作为早期稻粟农业重要传出地的云贵高原和福建 沿海, 其早期遗址都是稻粟组合, 而这个组合在中南半 岛被拆散，至少现在的证据支持当地最先出现的是单 一的粟作农业，而水稻在南传的过程中被“丢失”了. 与水稻相比，粟和乘的谷粒小而不易被保存和发现， 所以应该可以排除早期水稻遗存没有被发现的情况. 那么早期农业从传出地向东南亚大陆传播的过程中是 否延续了稻粟组合的方式? 如果是，为什么会率先接 受粟作农业？如果不是，水稻又是什么时候“丢失” 的呢?

中南半岛最早的粟作出现在KWP地区，研究者指 出，该地区河流阶地和山前阶地土壤有很大区别- 
河流阶地是相对肥沃的黏土，遗址所在的山前阶地是 渗水能力较强的粉砂质土壤, 适宜开展旱作农业(Weber等, 2010). 古环境研究表明, 当地在新石器晚期林 木减少、草本植物增加，就气候而言也更适宜旱地农 业发展(Kealhofer, 2002). 所以距今4400年前粟作农业 首先在KWP地区出现, 很可能是史前人类为适应当地 生态环境所采取的生存策略. 另外, 中南半岛早期的稻 作生产都是旱稻，不同于中国南方的水稻(Fuller等, 2011; Martelloa等, 2018). 由水稻到旱稻, 一方面可视 为作物对中南半岛自然环境的适应; 另一方面, 水稻对 当地环境的“水土不服”, 也是稻作传入较晚的原因 之一.

KWP地区的稻作农业直至公元前一千纪才出现. 相距不远的Khok Phanom Di遗址, 被认为在距今 4000 3500年前就开始利用水稻(Higham, 2002), 远远 早于KWP地区的稻作农业. 理论上KWP的聚落很早就 有接触稻作农业的机会, 只是一直将水稻拒之门外. 相 映成趣的是Khok Phanom Di遗址开展了密集的植物考 古工作，但始终没有发现粟和㯟的遗存. 也就是说， Khok Phanom Di遗址也有接触粟作农业的机会, 但是 也没有接受.

所以，一个聚落的生计策略与大的气候背景有关, 也受遗址小地貌、小生态乃至文化选择的影响. 基于 这点认识，再考虑史前农业向中南半岛的传播方式时， 就不能简单否定稻粟组合的方式. 因为不能排除同时 接触到两种作物而仅把其一纳入当地生业体系的可能 性; 但也不能排除早期农业在到达中南半岛南部之前 水稻已经“丢失”的可能性. 如果是后者，水稻又是何 时从何地传入中南半岛的呢? 要回答这些问题，正如 一再强调的, 还有待今后更多材料的检验.

\section{4 结论}

综上所述，中南半岛在公元前三千纪后期出现粟 作农业，至迟于公元前二千纪后期出现稻作农业. 多 个遗址的证据显示, 从新石器晚期到铁器时代, 粟作 农业一直在中南半岛的农业生产中占有重要地位。根 据目前的材料，中国福建沿海和西南内陆都有可能是 该地区稻粟农业的来源, 另外也不能排除两广地区单 一的稻作农业传播到中南半岛的可能性. 福建沿海的 稻粟农业很可能是通过海路到达中南半岛南部．在西 南内陆，来自长江中游的稻作和来自甘青地区的粟作
于公元前三千纪早期在成都平原汇合，然后以作物组 合的方式传播到云贵高原，再南传到中南半岛。早期 农业从成都平原到云贵高原，很有可能是沿着后世的 “施牛道”传播的; 从云贵高原到东南亚大陆的路线还 不清楚.

粟作和稻作的先后到达表明从中国向中南半岛扩 散的早期农业应该不止一波, 加之多源的传播途径, 使 得整个传播过程变得更为错综复杂. 这就更突显了考 古材料的重要性. 然而，区域内植物考古材料分布的 不平衡性在很大程度上制约了现有的研究工作. 尤其 是云南南部、中南半岛北部和两广内陆地区亟需系统 植物考古工作的开展和精准测年的支持. 另外, 农业的 传播和扩散不仅是人类活动和文化的产物，而且深受 自然环境的影响和制约, 尤其是早期农业. 所以, 在农 业传播过程中区域的气候环境背景和遗址的小地貌生 态背景都是未来需要开展的研究.

\section{参考文献}

阿坝藏族羌族自治州文物管理所, 成都文物考古研究所, 马尔康县 文化体育局. 2010. 四川马尔康县哈休遗址2006年的试掘. 南方 民族考古(第六辑). 北京: 科学出版社. 295-374

陈发虎, 安成邦, 董广辉, 张东菊. 2017. 丝绸之路与泛第三极地区人 类活动、环境变化和丝路文明兴衰. 中国科学院院刊, 32: 967975

成都文物考古研究院, 凉山彝族自治州博物馆, 盐源县文物管理所. 2016a. 盐源县的家堡遗址2015年度调查试掘简报. 成都考古发 现(2014). 北京: 科学出版社. 18-52

成都文物考古研究所, 凉山彝族自治州博物馆, 会理县文物管理所, 会东县文物管理所. 2016b. 2015年会理、会东县试掘遗址出土 植物遗存分析报告. 成都考古发现(2014). 北京：科学出版社. 135-146

崔勇. 2007. 广东高明古楖贝丘遗址发掘取得重要成果. 中国文物报. 1月 12 日 2 版

玳玉, 万娇. 2015. 四川什邡市桂圆桥遗址浮选结果与分析. 四川文 物, (5): 81-87, 94

广东省文物考古所, 封开县博物馆. 1998. 广东封开簕竹口遗址发掘 简报. 文物, (7): 38-41

广西壮族自治区文物工作队, 那坡县博物馆. 2003. 广西那坡县感驮 岩遗址发掘简报. 考古, (10): 35-56

广西壮族自治区文物工作队, 资源县文物管理所. 2004. 广西资源县 晓锦新石器时代遗址发掘简报. 考古, (3): 7-30

贵州省文物考古研究所, 四川大学历史文化学院考古系, 威宁县文 物保护管理所. 2006a. 贵州威宁县鸡公山遗址2004年发掘简报. 
考古, (8): 11-27

贵州省文物考古研究所, 四川大学历史文化学院考古系, 威宁县文 物保护管理所. 2006b. 贵州威宁县吴家大坪商周遗址. 考古, (8): 28-39

何锟宇. 2016. 试论宝墩文化的源头. 南方民族考古(第十二辑). 北 京: 科学出版社. 11-26

江章华. 2004. 峮江上游新石器时代遗存新发现的几点思考. 四川文 物, (3): 10-14

金和天, 刘旭, 闵锐, 李小瑞, 吴小红. 2014. 云南元谋大墩子遗址浮 选结果及分析. 江汉考古, (3): 109-114

墽勇. 1983. 云南耿马石佛洞遗址出土炭化古稻. 农业考古, (2): 8083

黎海明, 左昕听, 康利宏, 任乐乐, 刘峰文, 刘鸿高, 张乃梦, 闵锐, 刘 旭, 董广辉. 2016. 植物大化石和微体化石分析揭示的云贵高原 新石器——青铜时代农业发展历程. 中国科学: 地球科学, 46: 926-938

李昆声. 1998. 云南考古学论集. 昆明: 云南人民出版社

李映福. 2014. 川西高原区新石器时代至早期铁器时代生业经济的 考古学观察. 西南民族大学学报(人文社会科学版), (11): 14-20

闵锐. 2013. 剑川海门口遗址综合研究. 学园, (15): 6-9

屈小玲. 2011. 中国西南与境外古道: 南方丝绸之路及其研究述略. 西北民族研究, (1): 172-179

石涛. 2012. 成都平原先秦时期植物遗存研究. 硕士学位论文. 北京: 北京大学考古文博学院

四川省文物考古研究院, 阿坝藏族差族自治州文物管理所, 金川县 文化体育局, 壤塘县文化体育局. 2012. 四川金川县刘家寨遗址 调查简报. 四川文物, (5): 3-7

四川省文物考古研究院, 雅安市文物管理所, 汉源县文物管理所. 2011. 四川汉源龙王庙遗址2009年发掘简报．东方考古(第8集). 北京: 科学出版社. 406-442

孙传清, 王象坤, 吉村淳, 土井一行, 岩田伸夫. 1997. 普通野生稻和 亚洲栽培稻核基因组的RFLP分析.中国农业科学, 30: 37-44

孙华. 2009. 四川盆地史前谷物种类的演变——主要来自考古学文 化交互作用方面的信息. 中华文化论坛, (S2): 147-154

万娇. 2013. 苍洱地区史前文化. 北京: 文物出版社

万娇, 雷雨. 2013. 桂圆桥遗址与成都平原新石器文化发展脉络. 文 物, (9): 59-63

王大道. 1994. 再论云南新石器时代文化的类型. 西藏考古(第1集). 成都: 四川大学出版社. 91-108

王幼平. 1997. 中国南方与东南亚旧石器工业的比较. 考古学研究 (三). 北京: 科学出版社. 1-18

吴卫. 2018. 新石器时代稻作农业在中国东南沿海传播路径的新思 考. 农业考古, (4): 62-65

夏秀敏, 张萍, 吴妍. 2019. 广东珠江三角洲地区茶岭遗址的水稻遗 存分析. 第四纪研究, 39: 24-36

向安强, 姚锦鸿. 2006. 广东封开杏花河发现的古栽培稻及相关问题
探讨. 农业考古, (1): 33-45

肖明华. 2001. 云南考古述略. 考古, (12): 3-15

间雪, 郭富, 王育茜, 郭晓蓉. 2013. 四川阆中市郑家坝遗址浮选结果 及分析——兼谈四川地区先秦时期炭化植物遗存. 四川文物, (4): 74-85

严文明. 1990. 中国史前稻作农业遗存的新发现. 江汉考古, (3): 2732

云南省文物考古研究所，中国社会科学院考古研究所，成都文物考 古研究所, 临沧市文物管理所. 2010. 耿马石佛洞. 北京: 文物出 版社

张弛，洪晓纯. 2009. 华南和西南地区农业出现的时间及相关问题. 南方文物, (3): 64-71

张弛. 2017. 龙山-二里头一一国史前文化格局的改变与青铜时代 全球化的形成. 文物, (6): 50-59

张文绪, 向安强, 邱立诚, 姚锦鸿. 2008. 广东省封开县杏花河旧屋后 山遗址古稻双峰乳突及稃壳印痕研究. 中国水稻科学, 22: 103106

赵志军, 陈剑. 2011. 四川茂县营盘山遗址浮选结果及分析. 南方文 物, (3): 60-67

赵志军, 吕烈丹, 傅宪国. 2005. 广西邑宁县顶蛳山遗址出土植硅石 的分析与研究. 考古, (11): 76-84

中国社会科学院考古研究所东南工作队，福建博物院，明溪县博物 馆. 2018. 福建明溪县南山遗址. 考古, (7): 15-27

周拾禄. 1948. 中国是稻之原产地. 中国稻作, 7: 53-54

Barron A, Turner M, Beeching L, Bellwood P, Piper P, Grono E, Jones R, Oxenham M, Kien N K T, Senden T, Denham T. 2017. MicroCT reveals domesticated rice (Oryza sativa) within pottery sherds from early Neolithic sites (4150-3265 cal BP) in Southeast Asia. Sci Rep, 7: 7410

Bellwood P. 2011. The checkered prehistory of rice movement southwards as a domesticated cereal-From the Yangzi to the Equator. Rice, 4: 93-103

Bellwood P, Oxenham M, Hoang B C, Dzung N K, Willis A, Sarjeant C, Piper P, Matsumura H, Tanaka K, Beavan-Athfield N, Higham T, Manh N Q, Kinh D N, Kien N K T, Huong V T, Bich V N, Quy T T K, Thao N P, Campos F, Sato Y I, Cuong N L, Amano N. 2011. An son and the neolithic of southern Vietnam. Asian Perspect, 50: 144175

Castillo C. 2017. Development of creal agriculture in prehistoric mainland Southeast Asia. Man In India, 95: 335-352

Castillo C C, Fuller D Q, Piper P J, Bellwood P, Oxenham M. 2018. Hunter-gatherer specialization in the late neolithic of southern Vietnam-The case of Rach Nui. Quat Int, 489: 63-79

Castillo C C, Tanaka K, Sato Y I, Ishikawa R, Bellina B, Higham C, Chang N, Mohanty R, Kajale M, Fuller D Q. 2016. Archaeogenetic study of prehistoric rice remains from Thailand and India: Evidence 
of early japonica in south and southeast Asia. Archaeol Anthropol Sci, 8: 523-543

Clarkson C, Jacobs Z, Marwick B, Fullagar R, Wallis L, Smith M, Roberts R G, Hayes E, Lowe K, Carah X, Florin S A, McNeil J, Cox D, Arnold L J, Hua Q, Huntley J, Brand H E A, Manne T, Fairbairn A, Shulmeister J, Lyle L, Salinas M, Page M, Connell K, Park G, Norman K, Murphy T, Pardoe C. 2017. Human occupation of northern Australia by 65000 years ago. Nature, 547: 306-310

d'Alpoim Guedes J, Jiang M, He K, Wu X, Jiang Z. 2013. Site of Baodun yields earliest evidence for the spread of rice and foxtail millet agriculture to south-west China. Antiquity, 87: 758-771

Deng Z H, Hung H C, Carson M T, Bellwood P, Yang S L, Lu H Y. 2018b. The first discovery of Neolithic rice remains in eastern Taiwan: Phytolith evidence from the Chaolaiqiao site. Archaeol Anthropol Sci, 10: 1477-1484

Deng Z H, Hung H C, Fan X C, Huang Y M, Lu H Y. 2018a. The ancient dispersal of millets in southern China: New archaeological evidence. Holocene, 28: 34-43

Diamond J, Bellwood P. 2003. Farmers and their languages: The first expansions. Science, 300: 597-603

Fuller D Q. 2011. Pathways to Asian civilizations: Tracing the origins and spread of rice and rice cultures. Rice, 4: 78-92

Fuller D Q, Sato Y I, Castillo C, Qin L, Weisskopf A R, KingwellBanham E J, Song J X, Ahn S M, van Etten J. 2010. Consilience of genetics and archaeobotany in the entangled history of rice. Archaeol Anthropol Sci, 2: 115-131

Fuller D Q, Van Etten J, Manning K, Castillo C, Kingwell-Banham E, Weisskopf A, Qin L, Sato Y. Huimans R J. 2011. The contribution of rice agriculture and livestock pastoralism to prehistoric methane levels: An archaeological assessment. Holocene, 21: 743-759

Ge W, Yang S, Chen Y T, Dong S H, Jiao T L, Wang M Y, Wu M, Huang Y M, Fan X C, Yin X J, Zhang Y H, Tan Q G. 2019. Investigating the late neolithic millet agriculture in Southeast China: New multidisciplinary evidences. Quat Int, 529: 18-24

Hedges R E M, Housley R A, Bronk C R, Klinken G J V. 1991. Radiocarbon dates from the Oxford AMS system: Archaeometry datelist 13. Archaeometry, 33: 279-296

Hedges R E M, Housley R A, Ramsey C B, Klinken G J V. 1993. Radiocarbon dates from the Oxford AMS system: Archaeometry Datelist 17. Archaeometry, 35: 305-326

Higham C. 1996. The Bronze Age of Southeast Asia. Cambridge: Cambridge University Press

Higham C. 2002. Early Cultures of Mainland Southeast Asia. Bangkok: River Books Ltd

Higham C. 2003. Language and farming dispersals: Austroasiatic languages and rice cultivation. In Bellwood P, Renfrew C, eds.
Examining the Language/Farming Dispersal Hypothesis. Cambridge: McDonald Institute for Archaeological Research. 223-232

Higham C, Higham T. 2009. A new chronological framework for prehistoric Southeast Asia, based on a Bayesian model from Ban Non Wat. Antiquity, 83: 125-144

Jones M, Hunt H, Lightfoot E, Lister D, Liu X Y, MotuzaiteMatuzeviciute G. 2011. Food globalization in prehistory. World Archaeol, 43: 665-675

Kealhofer L. 2002. Changing perceptions of risk: The development of agro-ecosystems in Southeast Asia. Am Anthropol, 104: 178-194

Kealhofer L, Grave P. 2008. Land use, political complexity, and urbanism in mainland southeast Asia. Am Antiq, 73: 200-226

Kealhofer L, Piperno D R. 1994. Early agriculture in southeast Asia: Phytolith evidence from the Bang Pakong Valley, Thailand. Antiquity, 68: 564-572

Kharakwal J S, Yano A, Yasuda Y, Shinde V S, Osada T. 2004. Cord Impressed Ware and rice cultivation in South Asia, China and Japan: Possibilities of inter-links. Quat Int, 123-125: 105-115

Larson G, Piperno D R, Allaby R G, Purugganan M D, Andersson L, Arroyo-Kalin M, Barton L, Climer Vigueira C, Denham T, Dobney K, Doust A N, Gepts P, Gilbert M T P, Gremillion K J, Lucas L, Lukens L, Marshall F B, Olsen K M, Pires J C, Richerson P J, Rubio de Casas R, Sanjur O I, Thomas M G, Fuller D Q. 2014. Current perspectives and the future of domestication studies. Proc Natl Acad Sci USA, 111: 6139-6146

Lipson M, Cheronet O, Mallick S, Rohland N, Oxenham M, Pietrusewsky M, Pryce T O, Willis A, Matsumura H, Buckley H, Domett K, Nguyen G H, Trinh H H, Kyaw A A, Win T T, Pradier B, Broomandkhoshbacht N, Candilio F, Changmai P, Fernandes D, Ferry M, Gamarra B, Harney E, Kampuansai J, Kutanan W, Michel M, Novak M, Oppenheimer J, Sirak K, Stewardson K, Zhang Z, Flegontov P, Pinhasi R, Reich D. 2018. Ancient genomes document multiple waves of migration in Southeast Asian prehistory. Science, 361: 92-95

Lu H, Zhang J, Liu K B, Wu N Q, Li Y M, Zhou K S, Ye M L, Zhang T Y, Zhang H J, Yang X Y, Shen L C, Xu D K, Li Q. 2009. Earliest domestication of common millet (Panicum miliaceum) in East Asia extended to 10000 years ago. Proc Natl Acad Sci USA, 106: 73677372

Martelloa R, Min R, Stevens C, Higham C, Higham T, Qin L, Fuller D Q. 2018. Early agriculture at the crossroads of China and Southeast Asia: Archaeobotanical evidence and radiocarbon dates from Baiyangcun, Yunnan. J Archaeol Sci-Rep, 20: 711-721

Matsumura H, Hung H C, Higham C, Zhang C, Yamagata M, Nguyen L C, Li Z, Fan X C, Simanjuntak T, Oktaviana A A, He J N, Chen C Y, Pan C K, He G, Sun G P, Huang W J, Li X W, Wei X T, Domett 
K, Halcrow S, Nguyen K D, Trinh H H, Bui C H, Nguyen K T K, Reinecke A. 2019. Craniometrics reveal "two layers" of prehistoric human dispersal in eastern Eurasia. Sci Rep, 9: 1451

McColl H, Racimo F, Vinner L, Demeter F, Gakuhari T, Moreno-Mayar J V, van Driem G, Gram Wilken U, Seguin-Orlando A, de la Fuente Castro C, Wasef S, Shoocongdej R, Souksavatdy V, Sayavongkhamdy T, Saidin M M, Allentoft M E, Sato T, Malaspinas A S, Aghakhanian F A, Korneliussen T, Prohaska A, Margaryan A, de Barros Damgaard P, Kaewsutthi S, Lertrit P, Nguyen T M H, Hung H C, Minh Tran T, Nghia Truong H, Nguyen G H, Shahidan S, Wiradnyana K, Matsumae H, Shigehara N, Yoneda M, Ishida H, Masuyama T, Yamada Y, Tajima A, Shibata H, Toyoda A, Hanihara T, Nakagome S, Deviese T, Bacon A M, Duringer P, Ponche J L, Shackelford L, Patole-Edoumba E, Nguyen A T, Bellina-Pryce B, Galipaud J C, Kinaston R, Buckley H, Pottier C, Rasmussen S, Higham T, Foley R A, Lahr M M, Orlando L, Sikora M, Phipps M E, Oota H, Higham C, Lambert D M, Willerslev E. 2018. The prehistoric peopling of southeast Asia. Science, 361: 88-92

Oxenham M F, Piper P J, Bellwood P, Bui C H, Nguyen K T K, Nguyen Q M, Campos F, Castillo C, Wood R, Sarjeant C, Amano N, Willis A, Ceron J. 2015. Emergence and diversification of the neolithic in southern Vietnam: Insights from coastal Rach Nui. J Island Coast Archaeol, 10: 309-338

Ramsey C B, Higham T F G, Owen D C, Pike A W G, Hedges R E M. 2002. Radiocarbon dates from the Oxford AMS system: Archaeometry Datelist 31 . Archaeometry, 44: 1-150

Second G. 1985. Evolutionary relationships in the Sativa group of Oryza based on isozyme data. Genet Sel Evol, 17: 89-114

Sherratt A. 2006. The trans-Eurasian exchange: The prehistory of Chinese relations with the West. In: Mair V H, ed. Contact and Exchange in the Ancient World. Honolulu: Hawaii University Press. $32-53$

Silva F, Stevens C J, Weisskopf A, Castillo C, Qin L, Bevan A, Fuller D Q. 2015. Modelling the geographical origin of rice cultivation in
Asia using the rice archaeological database. PLoS One, 10: e0137024

Thompson G. 1996. The Excavation of Khok Phanom Di, a Prehistoric Site in Central Thailand. In: Vol. IV: Subsistence and Environment: The Botanical Evidence (The Biological Remains, Part II). London: The Society of Antiquaries of London

Tsang C H, Li K T, Hsu T F, Tsai Y C, Fang P H, Hsing Y I C. 2017. Broomcorn and foxtail millet were cultivated in Taiwan about 5000 years ago. Bot Stud, 58: 3

Weber S, Lehman H, Barela T, Hawks S, Harriman D. 2010. Rice or millets: Early farming strategies in prehistoric central Thailand. Archaeol Anthropol Sci, 2: 79-88

Yang X Y, Barton H J, Wan Z W, Li Q, Ma Z K, Li M Q, Zhang D, Wei J. 2013. Sago-type palms were an important plant food prior to rice in southern subtropical China. PLoS One, 8: e63148

Yang X Y, Wan Z W, Perry L, Lu H Y, Wang Q, Zhao C H, Li J, Xie F, Yu J C, Cui T X, Wang T, Li M Q, Ge Q S. 2012. Early millet use in northern China. Proc Natl Acad Sci USA, 109: 3726-3730

Yang X Y, Wang W W, Zhuang Y J, Li Z, Ma Z K, Ma Y C, Cui Y, Wei J, Fuller D. 2016. New radiocarbon evidence on early rice consumption and farming in South China. Holocene, 27: 1045-1051

Yang X, Chen Q, Ma Y C, Li Z, Hung H C, Zhang Q L, Jin Z W, Liu S Q, Zhou Z Y, Fu X G. 2018. New radiocarbon and archaeobotanical evidence reveal the timing and route of southward dispersal of rice farming in south China. Chin Sci Bull, 63: 1495-1501

Zhang C, Hung H C. 2010. The emergence of agriculture in southern China. Antiquity, 84: 11-25

Zhang C, Hung H C. 2012. Later hunter-gatherers in southern China, 18000-3000 BC. Antiquity, 86: 11-29

Zhang N M, Dong G H, Yang X Y, Zuo X X, Kang L H, Ren L L, Liu H G, Li H, Min R, Liu X, Zhang D J, Chen F H. 2017. Diet reconstructed from an analysis of plant microfossils in human dental calculus from the Bronze Age site of Shilinggang, southwestern China. J Archaeol Sci, 83: 41-48 